\title{
Budget Impact Analysis of a Pharmacist-Provided Transition of Care Program
}

\author{
Weiyi Ni, PhD; Danielle Colayco, PharmD, MS; Jonathan Hashimoto, PharmD; \\ Kevin Komoto, PharmD, MBA; Chandrakala Gowda, MD, MBA; Bruce Wearda, RPh; \\ and Jeffrey McCombs, PhD
}

\begin{abstract}
BACKGROUND: Postdischarge medication management services have been shown to reduce the incidence of medication-related problems during the transition from inpatient to outpatient care. A pharmacist-run transition of care (TOC) program has been developed to reduce the unplanned readmissions of a high-risk managed Medicaid population after hospitalization.
\end{abstract}

OBJECTIVE: To estimate the budget impact of adding an outpatient pharmacybased TOC program to a medical benefit from the payer perspective.

METHODS: A budget impact analysis was conducted using a decision-tree model developed in Microsoft Excel. The effect on inpatient and total health care costs from the payer perspective was estimated for the 2-year period following initial hospital discharge. Inputs were based on a total plan population of 240,000 lives, with a high-risk population of $7.5 \%$, of whom $37 \%$ were hospitalized and potentially qualified for TOC services, resulting in an eligible population of 6,660 patients. The TOC program was assumed to initially cover $30 \%$ of the eligible population, with expansion to $60 \%$ over the 2 years. We previously reported that this program reduced the risk of readmission by $32 \%$ within 6 months and saved the health plan $\$ 2,139$ per patient referred to the program, inclusive of program cost, compared with patients receiving usual discharge care. Sensitivity analyses were performed to test the impact of uncertainty of model inputs on the results, with the cost of TOC services ranging from $\$ 99$ to $\$ 2,000$ per patient referred.

RESULTS: The model showed that the TOC program was cost saving at over $\$ 3$ per member per month in the first 6 months, which translates to over $\$ 25$ million in total health care cost savings over 2 years. These results were primarily driven by the estimated reduction in inpatient costs associated with the program, which were estimated at \$20 million over the 2 years. Sensitivity analyses illustrated that within all the reasonable ranges of model input parameters, including the upper limit of TOC services set to $\$ 2,000$ per patient referred, the TOC program resulted in cost savings to the health plan.

CONCLUSIONS: The TOC program resulted in potential cost savings of over $\$ 25$ million to the managed Medicaid plan over a period of 2 years, corresponding to over $\$ 4$ per member per month.

J Manag Care Spec Pharm. 2018;24(2):90-96

Copyright $\odot 2018$, Academy of Managed Care Pharmacy. All rights reserved.

\section{What is already known about this subject}

The clinical and economic burden of hospital readmissions has been well established, with an estimated two thirds of postdischarge adverse events caused by medication-related problems. Pharmacist-provided transition of care (TOC) programs that provide medication reconciliation have been shown to reduce unplanned readmissions, which translates to lower health care costs.

\section{What this study adds}

This budget impact analysis showed that a pharmacist-run TOC program for a high-risk managed Medicaid population led to a cost avoidance of over $\$ 4$ per member per month within a 2-year horizon. This study can be used as a basic model for decision makers to evaluate their TOC programs.

T nappropriate use of medications during the transitional period following hospital discharge is a major contributing factor to hospital readmissions and increasing health care costs. ${ }^{1-3}$ Previous studies have demonstrated that adverse events related to medications are likely to occur during this transitional period, with an even higher risk for patients with more complex medication regimens. ${ }^{4-6}$ Medication management services after discharge, such as telephone follow-up, discharge counseling, and medication reconciliation have been shown to reduce the incidence of adverse drug events. ${ }^{7-10}$ Thus, transition of care (TOC) programs that incorporate medication management have been increasingly developed to reduce the risk of unnecessary readmissions and health care costs. ${ }^{11-14}$ The design and implementation of such programs may vary considerably. For example, some interventions occur in the inpatient setting before discharge, which may include "meds to beds" programs that deliver postdischarge medications directly to patients.

Other interventions, such as the program described in this study, focus on the postdischarge period in which patients are at risk for nonadherence, therapeutic duplications, and other medication problems related to discontinuity in care among multiple providers. Some programs focus primarily on medication review and reconciliation, while others take a more comprehensive approach to medication management. As a result, outcomes may vary depending on several factors, including the specific services provided, intensity level of the interventions, patient characteristics, and the skill level of the providers. ${ }^{15}$ Thus, it is meaningful to perform program-specific evaluations to show the effect of these programs.

Synergy Pharmacy Solutions (SPS) in Bakersfield, California, initiated a pharmacist-provided TOC program for adult members of Kern Health Systems (KHS) managed Medicaid health plan who were classified as high risk using the Johns Hopkins 


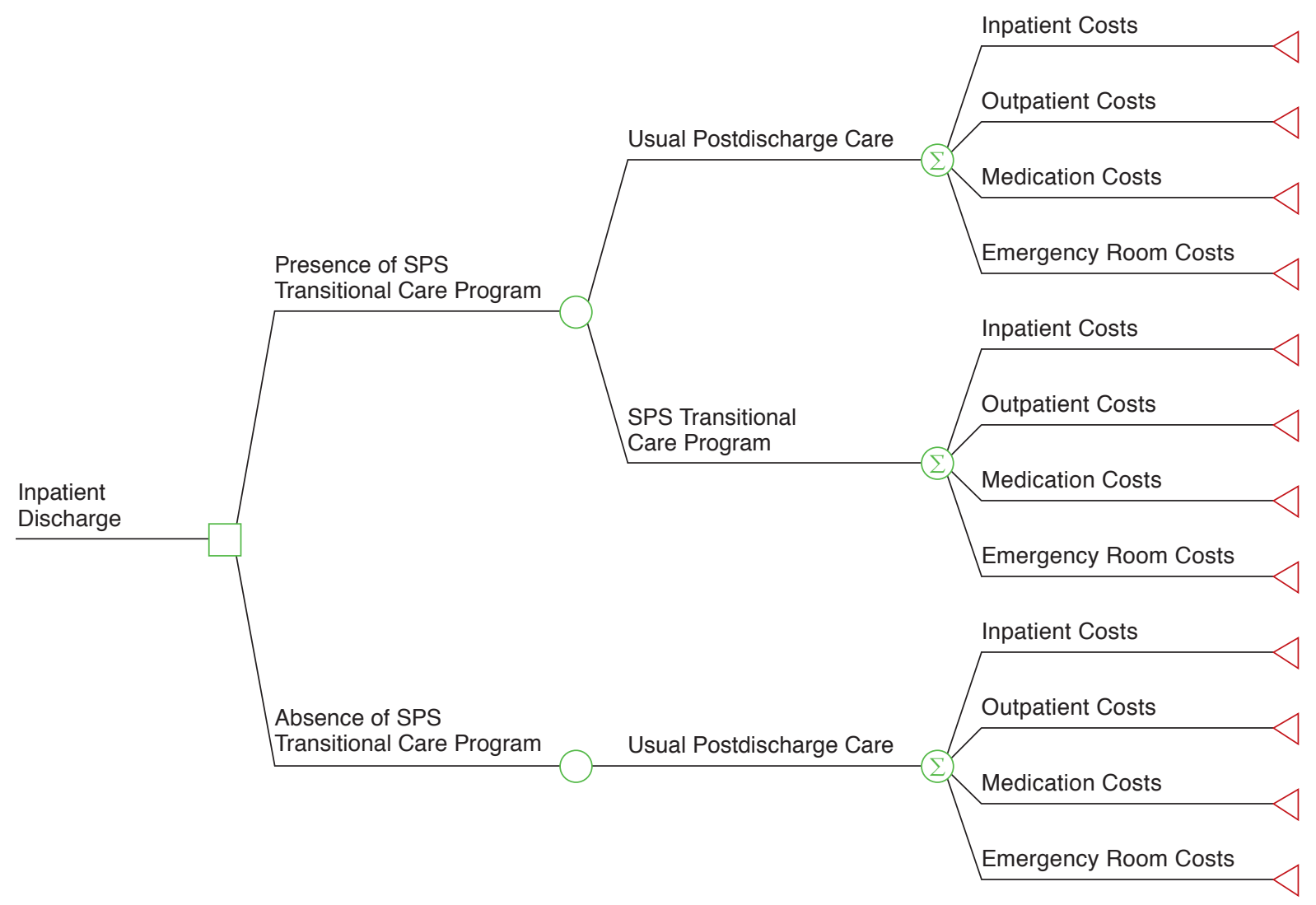

SPS=Synergy Pharmacy Solutions.

Adjusted Clinical Groups (ACG) predictive model, ${ }^{16}$ which is based on patient hospitalization history, prescription medication use, and social history. High-risk patients admitted to participating hospitals were referred to the SPS TOC program and contacted via telephone within 2 to 4 days after discharge. Once a referred patient agreed to participate, the SPS team provided comprehensive medication management, which included an assessment of all the patient's medications for appropriateness, effectiveness, safety, and adherence. Over the 30 days following discharge, the SPS pharmacy staff collaborated with the patient, caregivers, and outpatient providers to resolve any medication-related problems. Based on the clinical pharmacist's discretion, the specific interventions varied depending on the extent of each patient's medication-related issues.

Previous companion studies have evaluated the effects of the pharmacist-provided services at SPS on readmissions and health care costs at 30 days and 180 days after discharge..$^{13,14}$ These studies demonstrated that the SPS transitional services were associated with a $32 \%$ reduction in 30-day readmission risk and, consequently, decreased inpatient and total health care costs from the payer perspective. Given these findings, the investigators decided to create a budget impact model to simulate the economic effects of expanding the TOC services to more hospitals over time.

\section{Methods}

\section{Interventions}

Eligible patients were selected from the pool of KHS members who were admitted to 1 of the participating hospitals and who met at least 1 of the following criteria at the time of discharge: (a) high risk for readmission as determined by the Johns Hopkins ACG predictive model, ${ }^{16}$ (b) discharged with prescription claims for 5 or more medications, or (c) previously admitted to any hospital within the last 45 days.

Within 2 to 4 days after discharge, the SPS pharmacy staff contacted the patients at home to reconcile their actual medication use against the hospital discharge orders. Then, applying the principles of comprehensive medication management, the clinical pharmacists assessed the medications for appropriateness, effectiveness, safety, and ability to be taken as 
TABLE 1 Budget Impact Model Input Parameters

\begin{tabular}{|c|c|c|}
\hline Variables & $\begin{array}{c}\text { Input } \\
\text { Parameters }\end{array}$ & References \\
\hline \multicolumn{3}{|l|}{ Eligible population } \\
\hline Total KHS population & 240,000 & 13,14 \\
\hline KHS population increase rate (per 6 months) & $4.3 \%$ & 13,14 \\
\hline High risk & $7.5 \%$ & 13,14 \\
\hline Transitional care service coverage & $30.0 \%$ & 13,14 \\
\hline $\begin{array}{l}\text { Transitional care coverage increase rate } \\
\text { (per } 6 \text { months) }\end{array}$ & $7.5 \%$ & 13,14 \\
\hline $\begin{array}{l}\text { Hospital admission rate of high-risk } \\
\text { population (per } 6 \text { months) }\end{array}$ & $37.0 \%$ & 13 \\
\hline \multicolumn{3}{|l|}{ Health care utilization and costs, $\$$} \\
\hline $\begin{array}{l}\text { Average 6-month health care cost with } \\
\text { standard postdischarge care }\end{array}$ & $8,383.14$ & 14 \\
\hline $\begin{array}{l}\text { Average 6-months inpatient cost with } \\
\text { standard postdischarge care }\end{array}$ & $5,650.20$ & 14 \\
\hline $\begin{array}{l}\text { 6-month health care cost savings with SPS } \\
\text { transitional care }\end{array}$ & $2,139.35$ & 14 \\
\hline 6-month inpatient health care cost savings & $1,723.00$ & 14 \\
\hline Average TOC costs per patient & 98.88 & 14 \\
\hline National average inpatient costs & $13,655.00$ & 23 \\
\hline
\end{tabular}

directed. ${ }^{17}$ Over the 30 days following inpatient discharge, the pharmacy team also communicated with outpatient providers to resolve any medication-related problems, such as inappropriate therapy, therapeutic duplications, insurance issues, and drug interactions. At the discretion of the clinical pharmacists, patients with particularly complex regimens were invited for a face-to-face visit for more intensive counseling and assistance (less than $10 \%$ of cases).

\section{Budget Impact Model}

For U.S. payers, budget impact analysis has become an essential part of a comprehensive economic assessment of health care interventions. A budget impact model can help decision makers predict the expected changes in health care spending after adopting any new interventions and/or medications..$^{18-20}$

For this study, a budget impact analysis was conducted using a decision-tree model developed in Microsoft Excel (Microsoft Corp., Redmond, WA). Built from the payer perspective, the analysis modeled the impact of the SPS TOC program expansion to additional participating hospitals on total health care costs, including inpatient, outpatient, medication and emergency room costs, in 6-month increments up to 2 years (Figure 1). A 2-year horizon was selected in order to model a feasible time line for expansion of the program to additional hospitals.

Two scenarios were simulated: the presence and absence of the SPS TOC program. In the presence of the SPS TOC program, qualified patients discharged from participating hospitals were referred to SPS for services, while equally qualified patients from nonparticipating hospitals were provided the usual postdischarge care only. In the absence of the SPS program, all patients received the usual postdischarge care, which included medication reconciliation and discharge counseling in the inpatient setting, with no postdischarge medication management services. The cumulative inpatient and total health care costs over 2 years were then compared across the 2 scenarios.

\section{Data Inputs}

KHS Health Care Plan. In 2016, KHS covered approximately 240,000 lives, and this population increased about $8.7 \%$ from December 2015 to December 2016. ${ }^{21,22}$ Approximately 7.5\% of the KHS members met the referral criteria for high risk and were qualified for the SPS TOC program. Thirty-seven percent of this high-risk population $(n=6,600)$ were hospitalized and potentially eligible for SPS TOC services within 6 months. Of the hospitalized, high-risk members, about approximately 30\% had been admitted to the participating hospital, for a total of 1,998 patients (Appendix A, available in online article). Over the course of the next 2 years, the SPS TOC program was expected to double the number of members covered (Table 1).

Health Care Utilization and Costs. Health care utilization and costs of the patient population were previously estimated using KHS paid claims data in companion studies. ${ }^{13,14}$ The average 6-month total health care and inpatient costs of the high-risk population using standard postdischarge services were $\$ 8,383$ and $\$ 5,650$, respectively. The average cost of SPS TOC services was $\$ 99$ per patient referred. After accounting for these program costs, the 6-month net savings for patients in the SPS TOC program was $\$ 2,139$ in total costs and $\$ 1,723$ in inpatient costs.

\section{Sensitivity Analyses}

In order to test the effect of the uncertainty of model inputs on the results, 2 types of sensitivity analysis were applied.

One-Way Sensitivity Analysis for Total Health Care Costs. For the modeling of total health care costs, one-way sensitivity analysis was performed to show the range of budget impact estimates affected by variations in key input parameters (Appendix B, available in online article). Several drivers of total health care costs were identified, including the cost savings of the TOC program, the proportion of high-risk members, the proportion of hospitalized high-risk members, the proportion of members receiving TOC services, the plan population size, and the cost of TOC services. In the one-way sensitivity analysis, input values of these factors were changed within plausible ranges as calculated from KHS administrative claims, as seen in the literature and as advised by clinical experts (Appendix B). ${ }^{13,14}$ The increase in the KHS population rate was set as $\pm 100 \%$ of the base value, and the range of the high proportion and 
TABLE 2 Budget Impact Analysis on Health Care Costs

\begin{tabular}{|c|c|c|c|c|c|}
\hline & $\begin{array}{c}\text { Year } 1 \\
\text { First } 6 \text { Months }\end{array}$ & $\begin{array}{c}\text { Year } 1 \\
\text { Second } 6 \text { Months }\end{array}$ & $\begin{array}{c}\text { Year } 2 \\
\text { First } 6 \text { Months }\end{array}$ & $\begin{array}{c}\text { Year } 2 \\
\text { Second } 6 \text { Months }\end{array}$ & Total \\
\hline \multicolumn{6}{|c|}{ Total health care costs, $\$$} \\
\hline \multicolumn{6}{|c|}{ Scenario 1: With transitional care } \\
\hline Standard care & $39,519,970.71$ & $36,802,972.73$ & $33,779,240.49$ & $30,427,418.58$ & $140,529,602.51$ \\
\hline Transitional care & $12,614,829.86$ & $16,446,584.44$ & $20,584,545.08$ & $25,047,960.61$ & $74,693,919.99$ \\
\hline Total costs & $52,134,800.58$ & $53,249,557.16$ & $54,363,785.57$ & $55,475,379.18$ & $215,223,522.49$ \\
\hline \multicolumn{6}{|c|}{ Scenario 2: No transitional care } \\
\hline Standard care & $56,457,101.02$ & $58,884,756.36$ & $61,416,800.89$ & $64,057,723.32$ & $240,816,381.59$ \\
\hline Budget impact & $-4,322,300.44$ & $-5,635,199.20$ & $-7,053,015.32$ & $-8,582,344.14$ & $-25,592,859.10$ \\
\hline PMPM & -3.00 & -3.75 & -4.50 & -5.25 & -4.17 \\
\hline \multicolumn{6}{|l|}{ Inpatient costs, \$ } \\
\hline \multicolumn{6}{|c|}{ Scenario 1: With transitional care } \\
\hline Standard care & $26,636,288.85$ & $24,805,043.99$ & $22,767,061.58$ & $20,507,948.15$ & $94,716,342.57$ \\
\hline Transitional care & $7,932,517.87$ & $10,342,020.17$ & $12,944,072.45$ & $15,750,778.83$ & $46,969,389.32$ \\
\hline Total costs & $34,568,806.72$ & $35,147,064.17$ & $35,711,134.03$ & $36,258,726.98$ & $141,685,731.89$ \\
\hline \multicolumn{6}{|c|}{ Scenario 2: No transitional care } \\
\hline Standard care & $38,051,841.22$ & $39,688,070.39$ & $41,394,657.42$ & $43,174,627.68$ & $162,309,196.71$ \\
\hline Budget impact & $-3,483,034.49$ & $-4,541,006.22$ & $-5,683,523.39$ & $-6,915,900.71$ & $-20,623,464.81$ \\
\hline PMPM & -2.42 & -3.02 & -3.63 & -4.23 & -3.36 \\
\hline
\end{tabular}

members receiving TOC services was set to $\pm 33 \%$. The cost savings associated with SPS transitional care services ranged from $\$ 1,000$ to $\$ 6,000$ based on the results of one of the companion studies. ${ }^{14}$ Finally, the range of cost of the TOC program was set from $\$ 50$ to $\$ 2,000$ per patient referred.

Sensitivity Analysis for Inpatient Costs. The main goal of the SPS TOC program was to reduce potentially preventable hospital readmissions in the high-risk population. Claims data from one of the companion studies were used to estimate the hospitalizations avoided through the SPS TOC program. For every 100 patients receiving transitional care services, 20 readmissions were avoided within a 6 -month period. ${ }^{13}$ Actual costs of each hospitalization were based on KHS claims data for the base case, while the sensitivity analysis used the national average inpatient costs from the Healthcare Costs and Utilization Project (HCUP). ${ }^{23}$ By applying national averages to the model, the robustness of the inpatient results could be tested in the hypothetical case of providing services to a different population.

\section{Results}

The budget impact model showed that in the first 6 months, the SPS TOC program resulted in cost avoidance of over $\$ 4.3$ million in total health care costs to the KHS plan, which corresponded to $\$ 3$ per member per month. With the expansion of the program (i.e., doubling the number of members served) by the end of year 2, the savings reached over $\$ 4$ per member per month, for a total of $\$ 25.6$ million (Table 2). The inpatient cost savings were estimated at over $\$ 3.5$ million in the 6 months after discharge, with a cumulative 2-year inpatient cost savings of $\$ 20.6$ million (Table 2 ).
The one-way sensitivity analysis of the budget impact on total health care cost was used to evaluate the robustness of the model in the presence of the uncertainty of input parameters. Within the expected ranges of key input parameters, the 2-year total health care cost savings from the SPS TOC ranged from $\$ 12$ million to $\$ 72$ million and were most sensitive to the cost savings of the SPS TOC per patient referred. Other key drivers included the proportion of members receiving the TOC services and the cost of the TOC program (Figure 2). The higher the proportion of members receiving the program (i.e., more high-risk members, more hospitalized members, and/or more members served by the TOC program), the higher the cost savings. In the most conservative scenario, in which the cost of the TOC program was set to $\$ 2,000$ per patient referred, the program was still cost saving at over $\$ 2.8$ million within 2 years.

The sensitivity analysis on inpatient costs was performed using the national average inpatient costs from HCUP. Compared with the average inpatient costs calculated from the KHS administrative data, the national average inpatient cost was higher $(\$ 13,655$ vs. \$8,383). Combined with the estimated readmissions avoided through the SPS TOC program, an even higher inpatient cost savings was realized in this scenario, at $\$ 5.4$ million at 6 months and a cumulative 2-year savings of over $\$ 32$ million (Table 3).

\section{Discussion}

The economic effects of the SPS pharmacy-based TOC program on health care utilization and costs have been previously studied and were found to reduce readmissions and health care 


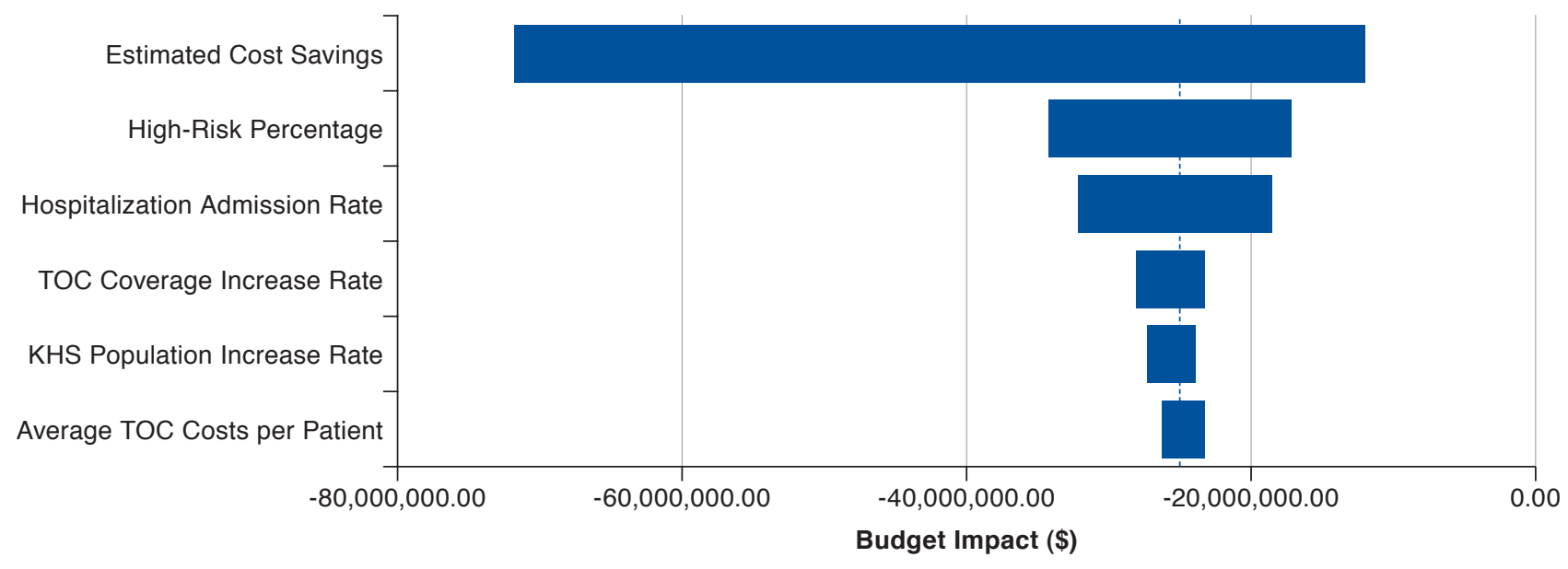

KHS = Kern Health System; TOC= transition of care.

costs after inpatient discharge. ${ }^{13,14}$ Based on these results, the health plan decided to evaluate the potential effect of expanding the program to additional hospitals. Thus, a decision tree model was developed to simulate the budget impact within a time horizon of 2 years. In accordance with the ISPOR Principles of Good Practice for Budget Impact Analysis, ${ }^{19}$ the model was built from the payer's perspective, using its own administrative claims data for the majority of key inputs. ${ }^{13,14}$

A one-way sensitivity analysis was performed to verify the robustness of the budget impact model. Within reasonable ranges of model input parameters, the results showed that the SPS TOC program was cost saving in all scenarios tested. The sensitivity analysis also identified key factors affecting cost savings, such as the number of patients who qualified for the program, as well as the number of patients able to access the transitional care program.

Along with the one-way sensitivity analysis, an additional analysis on the inpatient costs was performed to test the generalizability of the model to populations outside of KHS, assuming similar effectiveness of the intervention. In this scenario, the effect of the program was estimated using the national average inpatient costs from HCUP, ${ }^{23}$ assuming the same reduction in readmissions as in the base case. Since the national average inpatient costs were around $\$ 5,000$ higher than the average from the KHS Medicaid plan, the sensitivity analysis showed a higher inpatient cost savings if the TOC program were provided to a more nationally representative patient population.

\section{Limitations}

This study has a number of limitations to be considered. First, a predictive analysis was required, so several input parameters including the KHS plan population, the proportion of members potentially eligible for TOC services, and the accessibility to the service needed to be predicted and applied. However, those values had to be either estimated from historical data or projected based on the health plan's best estimates. In addition, the persistence of effect of the TOC program beyond 6 months had to be projected. In this model, it was assumed that the effect would continue through the end of year 2 . Although the current model was unable to avoid these uncertainties, the wide range of plausible values tested in the sensitivity analysis verified that the estimated cost savings did not change significantly.

Second, this study was based on a high-risk managed Medicaid population, which may limit the generalizability of the results to Medicare or commercially insured populations. In addition, since the program was implemented by a payer, the outcomes may differ from programs developed by hospitals or other health systems. In all scenarios tested, it was assumed that the TOC program would have the same effectiveness, which would limit the generalizability to programs with very different designs and patient populations.

Third, the additional operating costs of expanding the TOC program were not included, which could possibly affect the predicted cost savings. To account for this potential uncertainty, the costs of the TOC program were varied in the oneway sensitivity analysis up to a maximum of $\$ 2,000$ per patient referred, which still resulted in cost savings to the health plan.

Finally, the national average inpatient costs from HCUP were applied in a sensitivity analysis. ${ }^{23}$ However, this project was conducted in 2013, and the estimated health care costs may have changed over time. Should more recent studies be conducted on the same topic, the input value of this variable should be updated accordingly. 


\section{TABLE 3 Sensitivity Analysis Using HCUP Data on Budget Impact of Inpatient Costs}

\begin{tabular}{|c|c|c|c|c|c|}
\hline & $\begin{array}{c}\text { Year } 1 \\
\text { First } 6 \text { Months }\end{array}$ & $\begin{array}{c}\text { Year } 1 \\
\text { Second } 6 \text { Months }\end{array}$ & $\begin{array}{c}\text { Year } 2 \\
\text { First } 6 \text { Months }\end{array}$ & $\begin{array}{c}\text { Year } 2 \\
\text { Second } 6 \text { Months }\end{array}$ & Total \\
\hline \multicolumn{6}{|c|}{ Scenario 1: With transitional care, $\$$} \\
\hline Standard care & $40,876,652.67$ & $38,066,382.80$ & $34,938,848.79$ & $31,471,962.11$ & $145,353,846.36$ \\
\hline Transitional care & $12,083,671.90$ & $15,754,087.24$ & $19,717,815.59$ & $23,993,295.27$ & $71,548,870.01$ \\
\hline Total costs & $52,960,324.57$ & $53,820,470.04$ & $54,656,664.38$ & $55,465,257.38$ & $216,902,716.38$ \\
\hline \multicolumn{6}{|c|}{ Scenario 2: No transitional care, $\$$} \\
\hline Standard care & $58,395,218.10$ & $60,906,212.48$ & $63,525,179.61$ & $66,256,762.34$ & $249,083,372.53$ \\
\hline Budget impact & $-5,434,893.53$ & $-7,085,742.44$ & $-8,868,515.23$ & $-10,791,504.95$ & $-32,180,656.15$ \\
\hline PMPM & -3.77 & -4.72 & -5.66 & -6.60 & -5.24 \\
\hline
\end{tabular}

\section{Conclusions}

The budget analysis showed that expanding the SPS TOC program by doubling the eligible population will lead to potential cumulative cost savings of over $\$ 25$ million within 2 years, corresponding to over $\$ 4$ per member per month for this managed Medicaid plan. These results can be used by decision makers as a model for evaluating their own transitional care programs.

\section{Authors}

WEIYI NI, PhD, and JEFFREY MCCOMBS, PhD, Department of Pharmaceutical and Health Economics, School of Pharmacy, University of Southern California, Los Angeles. DANIELLE COLAYCO, PharmD, MS, Synergy Pharmacy Solutions and Komoto Family Foundation, Bakersfield, California. JONATHAN HASHIMOTO, PharmD, and KEVIN KOMOTO, PharmD, MBA, Synergy Pharmacy Solutions, Bakersfield, California. CHANDRAKALA GOWDA, MD, MBA, and BRUCE WEARDA, RPh, Kern Health Systems, Bakersfield, California.

AUTHOR CORRESPONDENCE: Weiyi Ni, PhD, Department of Health Outcomes Research, Millennium Health, 16981 Via Tazon, San Diego, CA 92127. Tel.: 352.871.6844; E-mail:weiyini@usc.edu.

\section{DISCLOSURES}

Funding for this study was contributed by the Komoto Family Foundation, which provided fellowships to Ni and McCombs during the time of this study. Colayco is employed by Synergy Pharmacy Solutions and by the Komoto Family Foundation. Hashimoto and Komoto are employed by Synergy Pharmacy Solutions. Gowda and Wearda report no relationship or financial interest with any entity that would pose a conflict of interest with the subject matter of this article.

Study concept and design were contributed by Ni, Colayco, and McCombs, along with the other authors. Hashimoto, Komoto, and Wearda took the lead in data collection, assisted by Ni, Colayco, and Gowda. Data interpretation was performed by Ni, Colayco, and McCombs, along with the other authors. The manuscript was written by $\mathrm{Ni}$ and Colayco and revised by Gowda and McCombs, along with the other authors.

\section{ACKNOWLEDGMENTS}

The authors gratefully acknowledge the staff and pharmacists at Synergy Pharmacy Solutions for their continued contributions towards patient care. In addition, we thank our colleagues at Kern Health Systems, especially Douglas Hayward, Deborah Murr, Jeff Pollock, and Pavan Tirumalasetty.

\section{REFERENCES}

1. O'Sullivan D, O'Mahony D, O'Connor MN, et al. The impact of a structured pharmacist intervention on the appropriateness of prescribing in older hospitalized patients. Drugs Aging. 2014;31(6):471-81.

2. Coleman EA, Smith JD, Raha D, Min SJ. Posthospital medication discrepancies: prevalence and contributing factors. Arch Intern Med. 2005;165(16):1842-47.

3. Sehgal V, Bajwa SJ, Sehgal R, Bajaj A, Khaira U, Kresse V. Polypharmacy and potentially inappropriate medication use as the precipitating factor in readmissions to the hospital. J Family Med Prim Care. 2013;2(2):194-99.

4. American Pharmacists Association, American Society of Health-System Pharmacists, Steeb D, Webster L. Improving care transitions: optimizing medication reconciliation. J Am Pharm Assoc (2003). 2012;52(4):e43-52.

5. Forster AJ, Murff HJ, Peterson JF, Gandhi TK, Bates DW. Adverse drug events occurring following hospital discharge. J Gen Intern Med. 2005;20(4):317-23.

6. Picker D, Heard K, Bailey TC, Martin NR, LaRossa GN, Kollef MH. The number of discharge medications predicts thirty-day hospital readmission: a cohort study. BMC Health Serv Res. 2015;15:282.

7. Al-Rashed SA, Wright DJ, Roebuck N, Sunter W, Chrystyn H. The value of inpatient pharmaceutical counselling to elderly patients prior to discharge. Br J Clin Pharmacol. 2002;54(6):657-64.

8. Dudas V, Bookwalter T, Kerr KM, Pantilat SZ. The impact of follow-up telephone calls to patients after hospitalization. Am J Med. 2001;111(9B):26S-30S.

9. Szkiladz A, Carey K, Ackerbauer K, Heelon M, Friderici J, Kopcza K. Impact of pharmacy student and resident-led discharge counseling on heart failure patients. J Pharm Pract. 2013;26(6):574-79.

10. Walker PC, Bernstein SJ, Jones JN, et al. Impact of a pharmacist-facilitated hospital discharge program: a quasi-experimental study. Arch Intern Med. 2009;169(21):2003-10

11. Jackson C, Kasper EW, Williams C, DuBard CA. Incremental benefit of a home visit following discharge for patients with multiple chronic conditions receiving transitional care. Popul Health Manag. 2016;19(3):163-70.

12. Stauffer BD, Fullerton C, Fleming N, et al. Effectiveness and cost of a transitional care program for heart failure: a prospective study with concurrent controls. Arch Intern Med. 2011;171(14):1238-43. 
13. Ni W, Colayco D, Hashimoto J, et al. Impact of a pharmacy-based transitional care program on hospital readmissions. Am J Manag Care. 2017;23(3):170-76

14. Ni W, Colayco DC, Hashimoto J, Komoto K, Wearda B, McCombs J. Reduction of healthcare costs through a transitions of care program. Am J Health Syst Pharm. Forthcoming.

15. Christensen M, Lundh A. Medication review in hospitalised patients to reduce morbidity and mortality. Cochrane Database Syst Rev. 2013(2):CD008986.

16. The Johns Hopkins University. The Johns Hopkins ACG system. Available at: https://www.hopkinsacg.org/. Accessed December 15, 2017.

17. McInnis T, Capps K. Get the medications right: a nationwide snapshot of expert practices. Comprehensive medication management in ambulatory/community pharmacy. Health2Resource. May 2016. Available at: http://0104.nccdn.net/1_5/20d/3cl/203/GetTheMedicationsRight.v22final-5.20.pdf. Accessed December 15, 2017.

18. Sullivan SD, Mauskopf JA, Augustovski F, et al. Budget impact analysis-principles of good practice: report of the ISPOR 2012 Budget Impact Analysis Good Practice II Task Force. Value Health. 2014;17(1):5-14.
19. Mauskopf JA, Sullivan SD, Annemans L, et al. Principles of good practice for budget impact analysis: report of the ISPOR Task Force on Good Research Practices_budget impact analysis. Value Health. 2007;10(5):336-47.

20. Marshall DA, Douglas PR, Drummond MF, et al. Guidelines for conducting pharmaceutical budget impact analyses for submission to public drug plans in Canada. Pharmacoeconomics. 2008;26(6):477-95.

21. Kern Health Systems. Regular meeting of the board of directors. 2016. Available at: http://www.kernfamilyhealthcare.com/files/KHS\%20Board\%20 packet\%20for\%20Dec.\%2015,\%202016.pdf. Accessed December 15, 2017.

22. Gowda C. Kern Health System transition of care model development report. Presented at: World Congress 3rd Annual West Physician Advisor \& Case Management Summit; San Diego, CA; October 19-20, 2015.

23. Barrett ML, Wier, LM, Jiang HJ, Steiner, CA. All-cause readmissions by payer and age, 2009-2013. HCUP Statistical Brief \#199. December 15, 2015. Agency for Healthcare Research and Quality. Rockville, MD. Available at: https://www.hcup-us.ahrq.gov/reports/statbriefs/sbl99-Readmissions-PayerAge.pdf. Accessed December 21, 2017. 


\section{APPENDIX A Model Population}

Total KHS Population

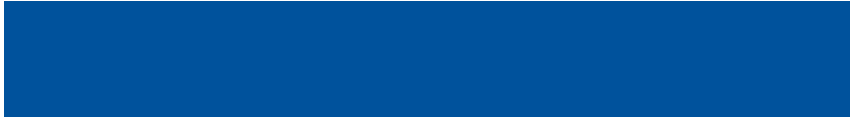

High-Risk Population

Hospitalized High-Risk Population

TOC-Covered Discharged Population
240,000

\section{APPENDIX B Input Parameters of One-Way Sensitivity Analysis}

\begin{tabular}{|c|c|c|c|c|}
\hline Input Parameters & Baseline Value & Lower Limit & Upper Limit & References \\
\hline KHS population increase rate & $4.3 \%$ & $0.0 \%$ & $8.0 \%$ & 13,14 \\
\hline High risk & $7.5 \%$ & $5.0 \%$ & $10.0 \%$ & 13,14 \\
\hline Transitional care coverage increase rate (per 6 months) & $7.5 \%$ & $5.0 \%$ & $10.0 \%$ & 13,14 \\
\hline Hospital admission rate of high-risk population (per 6 months) & $37.0 \%$ & $27.0 \%$ & $47.0 \%$ & 13,14 \\
\hline 6-month health care cost savings with SPS transitional care & $\$ 2,139.35$ & $\$ 1,711.00$ & $\$ 2,567.00$ & 13,14 \\
\hline Average TOC costs per patient & $\$ 98.88$ & $\$ 0.25$ & $\$ 3.00$ & 13,14 \\
\hline
\end{tabular}

